\title{
Business Environmental Factors: Implications on the Survival and Growth of Business Organisations in the Manufacturing Sector of Lagos Metropolis
}

\author{
Babalola Oluwayemi Oginni ${ }^{1} \&$ Abel Segun Adesanya ${ }^{2}$ \\ ${ }^{1}$ Department of Economics and Business Studies, Redeemer's University, Mowe, Ogun State, Nigeria \\ ${ }^{2}$ Department of Business Administration, Lagos State Polytechnic, Ikorodu, Lagos, Nigeria \\ Correspondence: Babalola Oluwayemi Oginni, Department of Economics and Business Studies, Redeemer's \\ University, Mowe, Ogun State, Nigeria. Tel: 234-802-812-2512. E-mail: isomes2011@gmail.com
}

Received: August 13, 2013

Accepted: September 18, 2013

Online Published: September 23, 2013

doi:10.5430/bmr.v2n3p146

URL: http://dx.doi.org/10.5430/bmr.v2n3p146

\begin{abstract}
The research work focused on the implication of the business environmental factors on the survival and growth of business organisations in the manufacturing sector with reference to Lagos metropolis of Nigeria. The study identified some environmental factors that were peculiar to the business organisations in the manufacturing sector vis-a-vis their significant impact through the administered questionnaires to employees of selected business organisations and inhabitants of three senatorial district that constitute Lagos metropolis. Electricity, government policies and fraudulent practices were found as factors critical with severe impact on the survival and growth of business organisations in the manufacturing sector among other factors which was adduced as the underlying rationale behind exodus of manufacturing organisations to the neighbouring countries. The use of $Z$ value of 1.96 at 0.05 level of significance further confirmed the impact of each of the environmental factors on the survival and growth of business organisations and concluded that these factors signified impending danger that may impede the survival of these business organisations and make growth an impossible task if left on, thus recommended among others that the present arrangement (policy) of centralising electricity which has made the federal government to enjoy monopoly should be jettisoned in order to make way for devolution and alternative to power generation aside the use of generator which has made operation cost to keep increasing.
\end{abstract}

Keywords: Environmental factors, Growth, Survival, Manufacturing sector, Lagos metropolis

\section{Introduction}

No business organization can operate successfully in isolation without dependence on supportive institutions, variables and factors (Oginni, 2010) i.e business organisation exists and operates within an environment where there is complex interplay in terms of activities as well as networks of relationship between and among human resources, material resources and other systems. In the views of Aborade (2005) all business decisions are found to be contingent upon a good analysis of the environment which is often the bane of all the constraints as this environment creates the opportunities, threats and problems for the business organisation. Evolving from this is the belief that business organization is an integral part of its environment on the ground that they are mutually interdependent and exclusive where the environment plays the role of providing the resources and opportunities to organization for its existence, and the business organization in turn, offers its goods and services to the people living in the environment for survival and enlightenment (Ajala 2005). This is also in line with the views of Adi (2006) that the most important sole influence on organizational policy and strategy at any point in its development is the environment, both within and outside the organization. Akanji (2003) was of the opinion that the more complex, turbulent and dynamic an environment becomes, the greater the impact on human attitudes, business, organizational structure, market and process as well as facilities, therefore there is need for all organizations to direct their attention to the environment when formulating their strategic management policies in order to facilitate their survival, growth and profit motives.

The paper was further divided into five parts: first, we introduce the study with concise description of the problem and objectives; second part clarifies some concepts involved in the focus of the study under the literature review and the third part centred on methodology. The interpretation of data represented the fourth part and the fifth part is on conclusion and recommendations. 


\subsection{Statement of the Problem}

The Nigerian business environment in the last one decade has witnessed unsatisfactory progress cumulating into retarded growth rate, high rate of unemployment, low industrial output, coupled with poor demand in terms of services and tangible products. Energy crisis continued unabated forcing majority of the organisations to depend wholly on generator as a constant source of generating electricity, supply of petroleum product is epileptic in addition to frequent changes in pump price resulting into increase in the general price level of all products without any exception due to cobweb effect; most of the organisations are ravaged with strikes from time to time. The relationship between industrial representatives and government institutions and representatives keep nose-diving virtually on all matters, criminal activities increasing at alarming and uncontrollable rate, exercising excessive control through plethora of rules and regulations with stringent conditions, tax policies without adequate provision of infrastructural facilities to ameliorate business operations. In the face of all these challenges, how effectively can a business organisation respond to its basic operational functions of survival, growth and profit maximisation, hence the need to examine the environmental factors in business environment of manufacturing organisations with implications on the survival and growth of business organisations in the Lagos metropolitan area of Nigeria.

\subsection{Objective of the study}

The main objective of the study was to examine the environmental factors in business environment of manufacturing organisations with implications on the survival and growth of business organisations in the Lagos metropolitan area of Nigeria. This was achieved through the following specific objectives;

1) to identify key issues involved in environmental factors towards business survival and growth;

2) to examine relationship between environmental factors and business survival and growth;

3) to determine the extent to which environmental factors affect business survival and growth;

4) to identify strategies that organisations can adopt in the wake of turbulent business environmental factors such as Lagos metropolitan business environment and;

5) to assess challenges confronting business survival and growth in the business environment of Lagos metropolitan business environment.

\subsection{Research Questions}

The following questions were highlighted to be the framework providing guidance for the research work;

1) What are the issues involved in environmental factors towards business survival and growth?

2) Is there any relationship between environmental factors and business survival and growth?

3) To what extent have environmental factors affect business survival and growth in Lagos metropolitan business environment?

4) What are the strategies that organisations can adopt in the wake of turbulent business environmental factors such as Lagos metropolitan business environment?

5) What are the various challenges confronting business survival and growth in the business environment of Lagos metropolitan business environment?

\subsection{Significance of the Study}

The research work provided insight into the dynamism of business environment through which major and minor constraints in the environment were identified, the role of environmental factors in ensuring as well as heralding survival and growth of business organisations in relation to danger posed by these environmental factors were identified. The work has equally placed environmental factors in the fore front of business survival and growth thus enlightening that the success of any business organisation is contingent on understanding the environmental factors.

\section{Literature Review}

The review of the relevant literatures provided a good frame work to understand all the concepts and constructs involved in the work with a view to guiding the work using other researchers' works as basis.

\subsection{Environment and Business Organisation}

Environment is expressed as the sum total of the external forces that influences individuals, businesses and communities (Oginni and Faseyiku, 2012). In the views of Adebayo etal (2005), environment is summarised as the surrounding of a phenomenon which from time dictate and shape the direction. Business organisation does not operate in vacuum; it operates within the environment where the production and distribution of goods and services are carried out. Duncan (1972) opined that as any other activity of the individual is greatly affected and usually controlled by his total social environment so is the business activity in which individuals or groups of individuals 
participate. In the process, there is interaction between business and environment. To Carrasco (2007) in Oginni (2012) environment has been seen as the totality of the factors that affect, influence, or determine the operations or performance of a business and this was interpreted by Azhar (2008) that environment determines what is possible for the organization to achieve. In a nutshell, environment is the combination of many factors both tangible and non-tangible elements that provides lifeblood support for the organizational success through provision of market for its products and services and also by serving as a source of resources to others. Therefore, the environment of a business is the aggregation of the pattern of all the external and internal conditions and influences that affect the existence, growth and development of the business.

In Adebayo etal (2005), environment can be divided into two namely internal and external and can then be deduced that business environment can be also be classified into two. By internal business environment, this is made up of variables or factors that organisation has control over and can easily manipulate to suit its purpose as may be dictated by the prevailing circumstances such as capital, personnel, profit, procedure, policy, structure, objective e.t.c. The external business environment is made up extraneous variables or factors which are outside the control of the organisational management and cannot be manipulated such as technology, politics, and government legislation. In addition are economic, socio-cultural and physical factors. Asheghian \& Ebrahimi (1990) and Grant (1999) in Adeoye (2012) identified another environmental variable from the external environment known as task environment which is found immediately outside the organisation and argued that the task environment is the closest environment of the organization with customers, suppliers, labour union, labour market, competitors, financial institutions and raw materials as the main elements of the environment which have direct influence on the organization unlike the other external environment that have indirect influence on the business organisation. Daft etal (1988) opined that the task environment is characterised by uncertainty because it is believed that the task environment which is connected with the short-run is somewhat more volatile than the general environment that is connected with the long-run and the environmental uncertainty arises from the organization's inability to predict its environment (Oluremi and Gbenga 2011).

Oluremi and Gbenga (2011) asserted that business organisation that wants to succeed must develop a clear understanding of the trends of business environment and forces that shape competition. The understanding in question will enable the organization to choose the appropriate strategy or strategies that fit the trends in the business environment arrived at through environmental scanning analysis with focus on the variables such as strengths, weaknesses, opportunities and threat (SWOT). The views of Adeoye (2012) was in support as he opined that the dynamic and rapidly changing environment in which most business organizations compete is important that organizations maintain their performance measurement system through adoption of appropriate strategies that would provide information found to be relevant to the issues that are of paramount importance. However, Ibidun and Ogundele (2013) was of the opinion that understanding the nature of business environment which can be classified into three namely dynamic (continuous changes), stable (relative changes) and unstable (frequent changes) would further help in repositioning the organisation through appropriate strategies while Ogundele (2005) added that the perception of the organizations about the nature of the business environment to a large extent depends on their size and industry in which it operates. The implication of this is that what constitute dynamic, stable or unstable business environment is contingent upon size and industry and that all business organisations can never be faced with the same nature of business environment (dynamic, stable or unstable) as each would derive its own peculiarity on the basis of size and sector of the economy it belongs to.

\subsection{Business Organisational Survival}

Business survival is described as the operation of business organisation on - going concern sometimes refers to as manage to stay in business (Akindele etal, 2012). In an attempt to respond to the activities that will enable organisation to operate on going - concern, organisations are constantly in the process of structuring and restructuring to keep abreast with these activities which do come in form of complexities to include leadership styles, changes, uncertainty, conflict, culture, technology, structure, competitive market, profitability and workplace motivation (Adeoye, 2012). In view of these complexities as challenges, organisation needs to strategically plan and develop the most appropriate and adaptive structure that will enable it to utilise and maximise its resources and ultimately achieve organisational objectives (Mullins, 2002 and Akindele etal, 2012).

\subsection{Business Organisational Growth}

In the views of Laosebikan etal (2013) organizational growth means different things to different organizations because there are many parameters a company may use to measure its growth. This is so because the ultimate goal of most organisations is profitability, most organisations will measure their growth in terms of net profit, revenue, and 
other financial data. Other criteria for assessing the organisational growth are volume of sales, number of employees, physical expansion, success of a product line, or increased market share (Lipton and Mark, 2003). In the views of Roberts and John (2004), organisational growth will be gauged by how well a firm does relative to the goals it has set for itself and in the same vein, Coffman etal (2002) in Oginni (2010) were of the opinion that the intention and desire to keep the business to operate on going concern definitely calls for growth of the organisation otherwise such organisations will cease to exist. Aluko etal (1999) however added another dimension to what organisational growth is all about by saying that it is something for which most organisations strive, regardless of their size.

\subsection{Relationship between environmental factors, Business survival and Growth}

Asika (2001) was of the opinion that analysis of business environment is the examination and appraisal of the opportunities and threats provided by the environment as well as the potential strengths and weaknesses the business possesses. Carrasco (2007) in Oginni (2012) however, opined that opportunities and threats are associated with external environment of a business while strengths and weaknesses are associated with internal environment of the business. Consequently, external analysis examines opportunities and threats that exist in the environment while internal analysis examines strengths and weaknesses within the business with a view of using these to combat the external forces. However, both opportunities and threats exist independently of the firm. To Oginni (2010), the internal environment is always manipulated in response to the dictate of the external environment in an attempt to meet organisational objectives and this belief was supported by the views of Ghazali etal (2010). Ghazali, etal (2010) analyzed the critical internal and external factors that affect firms strategic planning in Malaysia. The internal and external factors examined in their study included strengths, weaknesses, opportunities and threats. Their study showed that firm's strengths are related to their financial resources and the weaknesses are related to the firms' management. The study further revealed that the external factors which become opportunities to the firms are support and encouragement from the government, and that threats are the bureaucratic procedures that firms have to face in order to get plan approval and certificate of fitness.

In the works of Norzalita and Norjaya (2010) which investigated the role of the external environment in the market orientation-performance linkage among SMEs in the agro-food sector in Malaysia and found that market-technology turbulence and competitive intensity did not moderate the relationship between market orientation and business performance. Pulendran etal (2000) in their related work on business environment observed that the external environment in which organizations operate is complex and constantly changing and found that a significant characteristic of the external environment and business organisation is competition. This was supported by the views of Asika, (2001) that organizations that recognizes the presence and intensity of competition have a greater tendency to seek out information about customers for the purpose of evaluation and to use such information to their advantage thus enabling competition to drive business organizations to look for their customers in order to understand better ways to meet their needs, wants, and thereby enhances organizational performance (Azhar, 2008).

According to Alexander (2000), the dynamic and rapidly changing environment in which most organizations compete had made business environment (political, economic, socio-cultural, technological, e.t.c.) to have significant impact on organizational survival and performance (effectiveness, efficiency, increase in sales, achievement of corporate goals e.t.c.) thus, organizations should pay more attentions to their environment by conducting and embarking on periodic scanning. In a related work by Adeoye (2012), it was stated that in the manufacturing industry, environmental changes are continuously exerting new pressures on company performance and to respond to these changes, some companies within the apparel industry have formulated and implemented strategies to reorganize and reform the way products are manufactured and distributed to final consumers, thus, the impact of environmental factors on business performance towards profit objective is found to have an increasingly stronger interrelationship which require a more sophisticated business strategies. Ogundele and Opeifa (2004) summed it up in their related work on environment and entrepreneurship by saying that external environment and their factors helps visualize the analysis of business survival and growth in an attempt to enhance understanding of how environmental factors work together with the variables of business survival and growth to determine the future of business organisation.

\section{Methodology}

The researchers collected all data employed in the research work through the use of secondary and primary data. The secondary data were obtained from documented information such as textbooks, journal articles and gazettes. Primary source of the data collected was questionnaire which was designed and structured to use open and ended questions. The open ended questionnaire was used during the pilot study between December 2012 and February 2013 where the 200 respondents chosen from the existing manufacturing organisations and the inhabitants in the three senatorial districts (West, East and Central) that made up Lagos Metropolis through convenience sampling technique were 
asked to list out various environmental factors found in the work environment of business organisation. On the basis of the responses from the respondents, the most frequently identified factors were noted and those that were reported by $85 \%$ were selected and formed the basis of the design of the questionnaire in line with Likert 5 points rating scales ( strongly agreed $=5$, agreed $=4$, neutral $=3$, disagreed $=2$ and strongly disagreed $=1$ ).

The questionnaire was administered to 550 respondents in the three senatorial districts (West (190), East (150) and Central (210)) that made up Lagos metropolis with respect to random and purposive sampling techniques. Out of the 550 copies of the questionnaire administered, 518 copies were retrieved from the respondents and after sorting the questionnaires collected 429 copies of the questionnaire were found useful for the purpose of analysis thus representing $78 \%$ rate of respondents. Data obtained from the respondents were analysed by simple percentage and illustrated by table distribution as well as using descriptive, correlation and analysis of variance at 0.05 level of sig. to ascertain the relationship and factor impact

\section{Data Analysis and Interpretation}

Table 1. Demographic Information about the Respondents

\begin{tabular}{|c|c|c|}
\hline Variables & Frequency distribution & Percentage \\
\hline \multicolumn{3}{|l|}{ Gender } \\
\hline - $\quad$ Male & 291 & $68 \%$ \\
\hline - $\quad$ Female & 138 & $32 \%$ \\
\hline Total & 429 & $100 \%$ \\
\hline \multicolumn{3}{|l|}{ Marital Status } \\
\hline - $\quad$ Single & 107 & $25 \%$ \\
\hline - $\quad$ Married & 279 & $65 \%$ \\
\hline - $\quad$ Divorced & 18 & $4 \%$ \\
\hline - Widow & 25 & $6 \%$ \\
\hline Total & 429 & $100 \%$ \\
\hline \multicolumn{3}{|l|}{ Educational Level } \\
\hline - $\quad \mathrm{M} . \mathrm{Sc} / \mathrm{MBA}$ & 117 & $27 \%$ \\
\hline - $\quad$ B.sc/ BA/B.ED/HND & 214 & $50 \%$ \\
\hline - ICAN/NIM/CIPM/CIBN & 47 & $11 \%$ \\
\hline - $\quad \mathrm{ND} / \mathrm{NCE}$ & 51 & $12 \%$ \\
\hline Total & 429 & $100 \%$ \\
\hline \multicolumn{3}{|l|}{ Work Experience } \\
\hline - $\quad$ Less than $2 \mathrm{yrs}$ & 87 & $20 \%$ \\
\hline - $\quad 2 \mathrm{yrs}-4 \mathrm{yrs}$ & 118 & $28 \%$ \\
\hline - $\quad 5 y r s-7 y r s$ & 179 & $42 \%$ \\
\hline - $\quad$ 8yrs \& above & 45 & $10 \%$ \\
\hline Total & 429 & $100 \%$ \\
\hline \multicolumn{3}{|l|}{ Age Limit } \\
\hline - $\quad$ Less than 25 years & 63 & $15 \%$ \\
\hline - $\quad 25 \mathrm{yrs}-35 \mathrm{yrs}$ & 113 & $26 \%$ \\
\hline - $36 y r s-45 y r s$ & 201 & $47 \%$ \\
\hline - $\quad 46 \mathrm{yrs}-55 \mathrm{yrs}$ & 22 & $5 \%$ \\
\hline 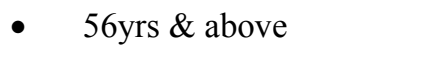 & 30 & $7 \%$ \\
\hline Total & 429 & $100 \%$ \\
\hline
\end{tabular}

Source: Survey 2013

The above table has information about the demographic status of the respondents. In the gender cadre 291 respondents were male representing $68 \%$ of the respondents while 138 respondents were female with $32 \%$ which showed that male respondents are the majority. It is also evident that in the marital status, it is dominated by married respondents with 279 respondents representing $65 \%$ followed by single respondents with 107 respondents representing $25 \%, 18$ respondents which represent $4 \%$ were divorced while $6 \%$ of the respondents were widow and 
there is no record of widower. The implication of this information is that the respondent's emotional crisis or trauma is minimal and relatively stable which means they are in best frame of mind to answer questions without prejudice. The educational level responses has that majority of the respondents are with first degree i.e 214 respondents with 50\% followed by second degree with 117 respondents representing $27 \%$, it is crystal clear that the respondents have what it takes to understand the questions without undue influence and also know the confidentiality and essence of research hence would not hoard any information. From the work experience responses, majority of the respondents were found in the range of 5yrs - 7yrs with 179 respondents representing $42 \%$ followed by 118 respondents in the range between $2 \mathrm{yrs}-4 \mathrm{yrs}$ representing $28 \%$. It can then be deduced that the years of experience in adequate to know, identify and express the likelihood effect of environmental factors in business survival and growth. From the age limit responses, the respondents in the age bracket of 36yrs - 45yrs were found to be the majority with 201 respondents representing $47 \%$, the implication of this is that the respondents are matured and candid can therefore be given without fear or favour.

Table 2. Environmental factors in manufacturing organisations in the Lagos Metropolis

\begin{tabular}{lllll}
\hline Environmental Factors /Variables & Number & Mean & Std. Dev & Mean Rank \\
\hline Electricity & 429 & 4.47 & 0.74 & 1 \\
Competition & 429 & 3.88 & 1.23 & 7 \\
Technology & 429 & 3.47 & 0.73 & 11 \\
Infrastructural Facilities & 429 & 4.21 & 0.82 & 4 \\
Capital & 429 & 3.77 & 085 & 9 \\
Government policies & 429 & 4.11 & 1.34 & 5 \\
Inflation & 429 & 3.13 & 0.87 & 12 \\
Raw materials & 429 & 3.87 & 0.92 & 8 \\
Organisational policies & 429 & 3.48 & 0.79 & 10 \\
Government politics & 429 & 4.23 & 0.84 & 3 \\
Financial credits & 429 & 4.38 & 0.89 & 2 \\
Fraudulent practices & 429 & 4.01 & 0.83 & 6 \\
\hline
\end{tabular}

Source: Survey questionnaire 2013

The above table has information about environmental factors in manufacturing organisations in the Lagos metropolis which showed the statistical results for the environmental factors. It thus revealed that electricity (mean $=4.47)$ is the most commonly found factor in the business environment of the manufacturing organisations. This was followed by financial credits as a factor in the business environment (mean $=4.38)$, next was government policies (mean $=3.48$ ), coming after this is infrastructural facilities $(4.21)$ followed by government policies (mean $=4.11)$, fraudulent practices $($ mean $=4.01)$, next in line was competition $($ mean $=3.88)$, after this was raw material $($ mean $=3.87)$, followed by capital $($ mean $=3.77)$, coming after this was organisational policies $($ mean $=3.48)$, technology $($ mean $=3.47$ ) was next and was followed by inflation (mean $=3.13$ ). The implication of this analysis was that electricity, financial credits, government policies, infrastructural facilities and capital were found to be major factors in the business environment of manufacturing organisation with significant impact on the survival and growth of these organisations. The table also indicated that the high scores showed that the manufacturing organisations strive towards survival and growth in the face of these factors that are not favourably to these organisations while the low scores of the standard deviations showed that there were no wide variations in the responses of the respondents.

Table 3. Percentage of Environmental Factors, Survival and Growth Dimensions

\begin{tabular}{lllllllllllll}
\hline Responses & EL & CO & TE & IF & CA & GP & IN & RM & OP & GOP & FC & FP \\
\hline Strongly Agreed & 65.3 & 37.3 & 54.4 & 44.3 & 37.8 & 48.3 & 17.5 & 2.8 & 48.2 & 34.2 & 27.5 & 44.3 \\
Agreed & 29.4 & 33.5 & 17.8 & 13.7 & 12.6 & 21.6 & 22.1 & 34.5 & 25.4 & 9.4 & 34.7 & 12.7 \\
Neutral & 5.3 & 14.6 & 10.3 & 25.5 & 34.6 & 22.5 & 10.7 & 8.4 & 9.3 & 10.5 & 9.3 & 24.4 \\
Disagreed & - & 12.2 & 12.8 & 15.4 & 10.3 & 4.2 & 34.2 & 40.5 & 14.8 & 35.6 & 17.2 & 14.1 \\
Strongly disagreed & - & 6.4 & 4.7 & 1.1 & 4.7 & 3.4 & 15.5 & 13.8 & 2.3 & 10.3 & 11.3 & 4.5 \\
Total & $\mathbf{1 0 0}$ & $\mathbf{1 0 0}$ & $\mathbf{1 0 0}$ & $\mathbf{1 0 0}$ & $\mathbf{1 0 0}$ & $\mathbf{1 0 0}$ & $\mathbf{1 0 0}$ & $\mathbf{1 0 0}$ & $\mathbf{1 0 0}$ & $\mathbf{1 0 0}$ & $\mathbf{1 0 0}$ & $\mathbf{1 0 0}$
\end{tabular}

Source: Survey questionnaire 2013 (EL = Electricity, $\mathrm{CO}=$ Competition, $\mathrm{TE}=$ Technology, IF $=$ Infrastructural Facilities, $\mathrm{CA}=$ Capital, GP $=$ Government policies, $\mathrm{IN}=$ Inflation, $\mathrm{RM}=$ Raw materials, $\mathrm{OP}=$ Organisational policies, $\mathrm{GOP}=$ Government politics, $\mathrm{FC}=$ Financial credits, $\mathrm{FP}=$ Fraudulent practices) 
The table above showed the dimensions of responses towards environmental factors, survival and growth of manufacturing organisations in terms of percentage. It was evident from the table that $65.3 \%$ of the respondents were of the opinion that at present electricity has a significant impact in the survival and growth of manufacturing organisations. The implication of this is that where the power supply in terms of electricity is epileptic, the survival and growth of manufacturing organisations in such vicinity would be severely hampered. It was also believed that the technology in the business environment of manufacturing organisations is followed with $54.4 \%$ of the respondents which means the extent of the stability in the changes in the technology would go a long way to determine the survival and growth of business in the manufacturing organisations. The respondents were of the opinion that the government policies with $48.3 \%$ have effect on the survival and growth of manufacturing organisations in the business environment i.e where the government policies is favourable, the likelihood of survival and growth would be high and vice versa. The way and manner by which the business organisation is being managed through organisational policies which has $48.2 \%$ would have effect on the survival and growth of the organisation.

This was followed by infrastructural facilities with $44.3 \%$ although about $25.5 \%$ of the respondents were sceptical as they don't know whether the idea should be supported or against. However, overall result showed that the level of infrastructural facilities would definitely affect the survival and growth of manufacturing organisations i.e where infrastructural facilities is low organisations would spend more and vice versa. It was not a surprise to find fraudulent practices in the environment of manufacturing business organisations with $44.3 \%$ of the respondents. The implication of this is that any kind of fraudulent practice would have negative impact on the business therefore the presence of fraudulent practices in the manufacturing business organisations would affect the survival and growth of business. The respondents' rate for capital of $37.8 \%$ of those who strongly believed that availability or access to capital affects the survival and growth of manufacturing business organisations was slightly above that of those who were neutral $34.6 \%$ indicating a thinly line to express where the pendulum is although the overall percentage of the respondents in support that availability or access to capital would affect the survival and growth of business organisation in the manufacturing sector. The majority of the respondents were of the opinion that competition with $70.8 \%$ has effect on the survival and growth of manufacturing business organisation.

However, it was found that raw materials have the highest percentage 40.5 from those that believed that it does not have effect on the survival and growth of business organisations in the manufacturing sector. This might be as a result of sourcing raw materials from local market as well as availability of the raw material from the local market in right quantity and quality. On the part of inflation, majority of the respondents believed that inflation does not have effect on the survival and growth of business organisations in the manufacturing sector. This may evolve from the thinking that the general rise in the cost of goods and materials would be borne by the final consumers i.e input price would determine the out price. The politics played by the government $35.6 \%$ was found to be insignificant in the course of determining the survival and growth of business organisations in the manufacturing sector as $34.2 \%$ respondents were of the that government politics would have effect on the survival and growth of business organisations in the manufacturing sector. The financial credits $34.7 \%$ as supported by financial institutions and supply of materials on credits would also have bearing on the survival and growth of business organisations in the manufacturing sector through provision of short and long term credit facilities to finance project operations.

Table 4. Computation of $Z$ value at 0.05 level of significance (two tailed test): $Z$ table value (1.96)

\begin{tabular}{lllllll}
\hline $\begin{array}{l}\text { Environmental Factors / survival } \\
\text { and growth dimensions }\end{array}$ & Number & Mean & Std. Dev & Std. Error & $\begin{array}{l}\text { Zalue } \\
\text { Calculated }\end{array}$ & $\begin{array}{l}\text { Mean } \\
\text { Rank }\end{array}$ \\
\hline Electricity & 429 & 4.47 & 0.74 & 0.11 & 1.74 & 1 \\
Competition & 429 & 3.88 & 1.23 & 0.12 & 1.67 & 7 \\
Technology & 429 & 3.47 & 0.73 & 0.11 & 1.86 & 11 \\
Infrastructural Facilities & 429 & 4.21 & 0.82 & 0.11 & 1.64 & 4 \\
Capital & 429 & 3.77 & 085 & 0.12 & 1.94 & 9 \\
Government policies & 429 & 4.11 & 1.34 & 0.12 & 0.88 & 5 \\
Inflation & 429 & 3.13 & 0.87 & 0.12 & 3.17 & 12 \\
Raw materials & 429 & 3.87 & 0.92 & 0.13 & 4.14 & 8 \\
Organisational policies & 429 & 3.48 & 0.79 & 0.12 & 1.84 & 10 \\
Government politics & 429 & 4.23 & 0.84 & 0.11 & 2.01 & 3 \\
Financial credits & 429 & 4.38 & 0.89 & 0.13 & 1.89 & 2 \\
Fraudulent practices & 429 & 4.01 & 0.83 & 0.11 & 1.45 & 6 \\
\hline
\end{tabular}

Source: $\quad$ Survey questionnaire 2013 
From the above table, the $Z$ calculated value for electricity is $1.74(\mathrm{Zcal}=1.74)$ and the $\mathrm{Z}$ tabulated value is 1.96 $(Z t a b=1.96)$, where Ztab is greater than Zcal (Ztab $1.96>$ Zcal 1.74) which means electricity plays a significant role in the survival and growth of business organisations in the manufacturing sector. The $Z$ calculated value for competition is 1.67 and the $\mathrm{Z}$ tabulated value is 1.96 which can be interpreted as Ztab $1.96>$ Zcal 1.67 i.e competition is a strong factor worthy of consideration in the wake of business survival and growth in the manufacturing sector as a result of the significant implication. Technology calculated value $(Z=1.86)$ and tabulated value (1.96) showed that the tabulated value is greater than the calculated i.e (Ztab $1.96>$ Zcal 1.86) which implied that technology has impact on the survival and growth of business organisations in the manufacturing sector. With respect to infrastructural facilities, calculated value $(Z=1.64)$ while tabulated value $(Z=1.96)$ which means that the tabulated value is greater than the calculated i.e (Ztab $1.96>$ Zcal 1.64) thus implying that the place of infrastructural facilities in the survival and growth of business organisations in the manufacturing sector is somewhat significant. The $\mathrm{Z}$ calculated value for capital is $1.94(\mathrm{Zcal}=1.94)$ and the $\mathrm{Z}$ tabulated value is $1.96(\mathrm{Ztab}=1.96)$ i.e $(\mathrm{Ztab} 1.96>$ Zcal 1.94). It can therefore be deduced that the role of capital in the survival and growth of business organisations in the manufacturing sector is quite significant and enormous. The $\mathrm{Z}$ calculated value for government policies is 0.88 $(\mathrm{Zcal}=0.88)$ and the tabulated value is $1.96(\mathrm{Ztab}=1.96)$ i.e $(\mathrm{Ztab} 1.96>\mathrm{Zcal} 0.88)$ which implies that government policies have a real significant impact on the survival and growth of business organisations in the manufacturing sector.

With respect to inflation, the calculated value $(Z=3.17)$ and the tabulated value $(Z=1.96)$ i.e (Ztab $1.96<Z$ cal 3.17) this implied that inflationary rate as it is being experienced in Lagos, Nigeria today is not quite significant as a factor in the survival and growth of business organisations in the manufacturing sector although it is recognised as a potential factor. The calculated value for the raw materials $(Z=4.14)$ and the tabulated value $(Z=1.96)$ can be represented as Ztab $1.96<$ Zcal 4.14 which means as at now the source of raw materials by these manufacturing organisations is considered to be adequate and therefore insignificant in the survival and growth of business organisations in the manufacturing sector although it is a potential factor. Organisational policies calculated value $(Z c a l=1.84)$ and the tabulated value $(Z t a b=1.96)$ implies that Zcal $1.84<Z$ tab 1.96 thus showed that organisational policies have a significant impact on the survival and growth of business organisations in the manufacturing sector. This is seen in the light of policy being a guide to action which is always multi dimensional. The $\mathrm{Z}$ calculated value for government politics is $2.01(\mathrm{Zcal}=2.01)$ while the $\mathrm{Z}$ tabulated value is $1.96(\mathrm{Ztab}=1.96)$ and can be expressed as $Z c a l 2.01>Z=$ tab 1.96 which can be deduced to mean that the present experience of government politics as at today does not have significant effect that can adversely affect the survival and growth of business organisations in the manufacturing sector although it is a potential force. Financial credits calculated value $(Z c a l=1.89)$ and the tabulated value $(\mathrm{Ztab}=1.96)$ i.e Zcal $1.89<\mathrm{Ztab}=1.96$ this showed that financial credits have significant impact on the survival and growth of business organisations in the manufacturing sector as organisations relied heavily on supply of materials while payments are schedule for another time. With reference to fraudulent practices, the $\mathrm{Z}$ calculated value $(\mathrm{Z}=1.45)$ and the tabulated value $(\mathrm{Z}=1.96)$ which can be interpreted as $\mathrm{Zcal} 1.45$ $<Z$ tab $=1.96$ therefore, fraudulent practices also have significant effect on the survival and growth of business organisations in the manufacturing sector.

\subsection{Discussion of Findings}

From the data analysis and interpretation, it was found that most of the factors identified as the environmental factors in the environment of the business organisations of the manufacturing sector have significant effect on the survival and growth of business organisations in the manufacturing sector which is in line with the stand of Alexander (2000) in his work on business environmental factor, survival and performance. Electricity is considered as one of the most important factors in the survival and growth of business organisations in the manufacturing sector simply because power generation is the sole and heart beat of operations in this sector and on the basis of this premise, it is clear why majority of the manufacturing organisations in Lagos being the economic nerve of the nation are constantly relocating to the neighbouring countries because of the epileptic supply of electricity from time to time in Lagos and in the country in general. This position corroborated the views of Ibidun and Ogundele (2013) which placed high premium on the nature of business and appropriate strategy to be adopted. Competition is another factor that is of importance which has equally threatened the survival and growth of business organisations in the manufacturing sector as a result of influx of substitute products from neighbouring countries which is even considered to be cheaper than those manufactured in the country which is supported by related work of Pulendran etal (2000) and Asika (2001) which recognised competition as a significant characteristic in the heart of business. It was also evident that most of these manufacturing organisations engaged in different kinds of fraudulent practices as way to breakeven or achieve their profit objective. However, factors such as inflation, raw materials and government politics were found to be 
potential factors but were in no way affect the survival and growth of business organisation in the manufacturing sector.

\section{Conclusion}

On the basis of the research findings, the existing environmental factors in the manufacturing sector were identified together with their respective significance impact or effect in the wake of survival and growth of the business organisations in the manufacturing sector of Lagos metropolis. Factors such as electricity, competition, technology, infrastructural facilities, capital, government policies, organisational policies, financial credits, fraudulent practices were found to show a direct significance in their relationship effect while inflation, raw materials and government politics were found to indicate indirect significance in their relationship effect. It is however crystal clear that all these factors identified were found to be challenges to the survival and growth of business organisations in the manufacturing organisations and where adequate attentions are not paid to these factors, it would definitely impede the survival of the business organisations thus making the growth impossible and where it is possible to be at snail pace.

\section{Recommendations}

Evolving from the above discussion, it is the opinion of the authors that if the following recommendations can be used as a blueprint towards providing a lasting solution to the survival and growth of business organisations in the manufacturing sector, it would be achieved in a time not far from now;

1) That the government of the day should endeavour to create an enabling environment that would be truly conducive for business organisations to thrive without engaging in any act of fraudulent practices.

2) That the present arrangement (policy) of centralising electricity which has made the federal government to enjoy monopoly should be jettisoned in order to make way for devolution and alternative to power generation aside the use of generator which has made operation cost to keep increasing since there is total collapse in the present arrangement.

3) That management of these manufacturing organisations should constantly scan the environment in order to understand the major trends of events and make proactive decisions that would neither jeopardise nor mortgaged the future of the organisations.

4) That the government of the day should make the business organisations in the manufacturing sector to enjoy certain tax rebate as a result of prevailing economic condition under which they conduct their businesses.

5) That funds in form of grants should be made available at the university levels to support science based researches for new discoveries in technology or improving on the existing one in order to adapt the technology to meet the domestic needs so as to further reduce cost associated with procurements.

6) That provision and maintenance of all infrastructural facilities should be of paramount importance in order to avoid complete decadence as it is found in the Lagos metropolis today, at the same, new one should be introduced to move with pace of technological advancement where necessary. Utmost premium should be placed on this for meaningful survival and growth of business in this sector.

7) That financial institutions should be strengthened in order to make loan available to these business organisations in the manufacturing sector so as to position these business organisations in such a way that availability of funds would not endanger the smooth operations of these organisations.

\section{Recommendations for further research}

With respect to some limitations in the course of the research work, the following are considered as areas that can be further researched into in the nearest future;

1) Evaluation of the environmental factors influence on the survival and growth of a business using econometric models

2) Correlational study of internal environmental factors of business and business survival.

\section{References}

Aborade R. (2005). A Practical Approach to Advanced Financial Accounting. $2^{\text {nd }}$ edition, Master Stroke Consulting.

Adebayo, I.O, Ogunyomi, P.O \& Ojodu, H.O: Introduction to Business Management, Oshodi - Lagos, Abilejo Printing Press.

Adeleke Adepoju. (2003). Business Policy and Strategy, $2^{\text {nd }}$ edition, Lagos, Concept Publication Limited. 
Adeoye A.O. (2012). Impact of External Business Environment on Organizational Performance on Food and Beverage Industry in Nigeria. British Journal of Arts and Social Sciences, Vol. 6 No. 2, pp 56-65.

Ajala, V.O. (2005). Public Relations: in search of professional Excellence, $2^{\text {nd }}$ edition, Ibadan, May Best Nigeria Limited.

Akindele, R.I, Oginni, B.O, \& Omoyele, S.O. (2012). Survival of Private Universities in Nigeria: Issues, Challenges and Prospects, International Journal of Innovative Research in Management. Vol. 1, (2) pp 30-43.

Adi, A.B.C. (2006). The Moral Economy and the Possibility of Accumulation in Africa How the IFIs can Help West Africa Review Vol. 3 (2), pp 34-49.

Alexander, D \& Britton, A. (2000). Financial Reporting, $5^{\text {th }}$ edition, London, Thomas Learning Publishing.

Akanji, S.O (2003). Business Environment in Nigeria, Mushin - Lagos, Datfore Ltd.

Asheghian, H.P. \& P, Ebrahimi. (1990). International Business, New York (NY), Harper Collins.

Asika, N. (2001). Understanding Nigerian Business Environment. First Edition, Lagos, Concept Publications.

Azhar, .K. (2008). Strategic Management and Business Policy, Tata, New Delhi McGraw-Hill Publishing Company limited.

Chuthamas Chittithaworn. (2011). Factors Affecting Business Success of Small and Medium Enterprises (SMEs) in Thailand, Asian Social Science.Vol7, No 5, pp 78-87.

Daft, R.L., L., Sarmunen, \& D., Parks. (1988). Chief Executive Scanning Environmental Characteristics and Company Performance: an empirical study, Strategic Management Journal, 9(2), 123- 139. http://dx.doi.org/10.1002/smj.4250090204

Duncan, R.B. (1972). Characteristics of organizational environments and perceived environmental uncertainty, Administrative Science Quarterly, 17, pp 313-327. http://dx.doi.org/10.2307/2392145

Ibidunni, O.S. \& Ogundele, O.J.K. (2013). Competition in Marketing, Survival Yardstick for Small and Medium Enterprises in Nigeria, Mediterranean Journal of Social Sciences, Vol.4 (1) pp $231-240$.

Laosebikan, J.S. (PhD), Oginni, B. O \& Ogunlusi, C. F. (2013). Evaluation of time management for growth and development in developing economies: Nigerian experience, International Journal of Innovative Research and Development, Vol.2 No7, pp $490-496$.

Mullins, J. Laurie. (2002). Management and organisational Behaviour 6th ed. Prentice - hall, Italy.

Ogundele, O. J. K and Opeifa, A. Z. (2004). The Influence of External Political Environment on the Processes of Entrepreneurship, the Nigerian Academic Forum: A Multidisciplinary Journal, Vol.7, No. 5, pp 7.

Ogundele, O.J.K. (2005). Management and Organization Theory and Behaviour, Lagos, Nigeria, Sabte Book Series.

Oginni, B.O. (2010). Business Organic Management, $2^{\text {nd }}$ ed. Somolu Lagos, Shecom Press Ltd.

Oginni, B.O \& Faseyiku, I.O. (2012). Fundamentals of Human Capital Management: A process approach, Mankore Print Ltd, Somolu - Lagos.

Oginni, B.O. (2012). The turbulent Business Environment in Nigeria, Somolu - Lagos Shecom Press Ltd.

Oluremi H.A \&. Gbenga M.A. (2011). Environmental Factors and Entrepreneurship, Development in Nigeria, Journal of Sustainable Development in Africa Vol. 13, No. 4, pp 127- 139. 